\title{
Formação continuada: \\ o processo de incorporação das novas tecnologias de informação e comunicação no trabalho do professor universitário
}

\author{
Continuing teacher formation: the process of \\ incorporation of new information and communication \\ technologies in the professor work
}

Márcia de Souza Hobold ${ }^{[a]}$, Silvia Simão de Matos ${ }^{[b]}$

[a] Doutora em Educação pela Pontifícia Universidade Católica de São Paulo (PUC-SP), professora do Departamento de Psicologia da Universidade da Região de Joinville (Univille), Joinville, SC - Brasil, e-mail: marcia.hobold@univille.br

${ }^{[b]}$ Especialização em Comunicação e Economia Política pela Pontifícia Universidade Católica do Rio Grande do Sul (PUCRS), é professor colaborador da Universidade da Região de Joinville (Univille), Joinville, SC - Brasil, e-mail: smattos@univille.br

\section{Resumo}

A formação continuada é um processo que perpassa a vida profisisonal dos professores e está presente tanto nos espaços formais de aprendizagem, quanto nas experiências reflexivas decorrentes das atividades profissionais docentes. Considerando esta temática, o 
presente artigo apresenta os resultados de uma pesquisa que teve como objetivo estudar o processo de desenvolvimento profissional de uma professora universitária diante da utilização das novas tecnologias de informação e comunicação (TICs) na sua prática docente. A coleta de dados contemplou: 1) a identificação de diferentes aspectos relacionados ao desenvolvimento do professor nos contextos pessoal, social e profissional; 2) o relato das principais mudanças apresentadas na sua prática docente a partir do uso das TICs; e 3) o reconhecimento dos estímulos internos e externos envolvidos no processo de mudança quanto ao uso de ferramentas tecnológicas. A professora pesquisada, identificada como Ana, trabalha há 54 anos na docência, dos quais, 33 anos como professora formadora do ensino superior. Fundamentaram teoricamente a pesquisa Huberman (1992), Vygotsky (1993, 2000), Lévy (1997), Romanowski (2007), Santos (2002) e Nóvoa (2000). Os resultados apontaram para a influência de significações constituídas no âmbito pessoal e profissional, destacando-se características como aprendizado constante, investimento permanente na sua formação, atuação com foco no aluno e estudo e desenvolvimento de estratégias inovadoras para o processo ensino-aprendizagem. A prática docente da professora formadora é permeada pela abstração e generalização de conceitos apreendidos nas interações sociais, culturais e históricas. A professora demostrou que, independente da idade, continua investindo na constituição da sua profissionalidade docente.

Palavras-chave: Formação continuada. Ciclo profissional dos professores. Tecnologias de informação e comunicação. Prática docente. Profissionalidade docente.

\section{Abstract}

The continuing teacher formation is a process that passes by the professional life of the professor and is present in both, the formal spaces of learning and the reflexive experiences related to the teaching professional activities. Bearing in mind this theme, the current article presents the results of a research that had the aim to study the process of a university teacher's professional development due to the use of the new information and communication technologies (ICT) in her teaching work. The collection of 
data has contemplated: 1) the identification of different aspects related to the professor's development in personal, social and professional contexts; 2) the story of the main changes presented in her practice from the use of the ICT; and 3) the recognition of the internal and external involved stimuli in the changing process, taking into consideration the use of technological tools. The investigated teacher, identified here as ANA, has been working for 54 years and, in 33 of these, as a superior teacher educator. The research has been based on Huberman (1992), Vygotsky (1993, 2000), Lévy (1997), Romanowski (2007), Santos (2002) and Nóvoa (2000). The results have pointed to the influence of the constituted signification in personal and professional scope, highlighting characteristics such as constant learning, and permanent investment in her teaching work, performance focused on the student, and study and development of innovative strategies for the teaching-learning process. The work of this teacher educator is permeated by the abstraction and generalization of apprehended concepts in social, cultural and historical interactions. The professor has demonstrated that, apart from age, she continues investing in the constitution of her teaching profissionality.

Keywords: Continued education. Professional life-cycle of teachers. Information and communication technologies. Teaching work. Teaching profissionality.

\section{Introdução}

Os espaços de trabalho presentes na sociedade brasileira têm sido marcados pela forte presença de recursos tecnológicos, de informática, de informação e de redes de comunicação. São ambientes de aprendizagem sustentados na utilização de recursos multimídias, de reuniões por videoconferência, de troca de mensagens em tempo real, enfim, de interação, comunicação e troca de informações num contexto global.

A atividade profissional do professor que atua na modalidade do ensino superior, em sua maioria, é mediada pelos recursos tecnológicos, sendo que a presença do computador é praticamente indispensável no dia a dia da sala de aula. Sua utilização independe da idade e/ou da classe social do professor e alunos. 
As tecnologias, inseridas no contexto da modernidade, faz com que o professor, especialmente no ensino superior, seja levado a desenvolver, rever e criar métodos de utilização desses e de tantas outras inovações. O professor universitário, em muitas das situações de ensino, reconhece a importância dos recursos tecnológicos nas estratégias que possam ser utilizadas em benefício do processo de aprendizagem.

Nesse sentido, foi desenvolvido um estudo de caso com uma professora, tendo como foco a atuação dessa profissional no ensino superior, o seu processo de formação continuada nas diferentes fases do ciclo profissional e o uso das Tecnologias de Informação e Comunicação (TICs) que permeia a sua prática e a constituição de significações pessoais e profissionais ao longo de sua trajetória.

É necessário levar em consideração que os espaços educacionais são múltiplos, as práticas inovadoras são necessárias e as ferramentas tecnológicas estão presentes em todos os ambientes. Essa realidade caracteriza-se, também, por constantes exigências de atualização, qualificação e formação permanente dos professores para esta realidade, ou seja, o processo de formação continuada dos professores precisa mais do que nunca compor o cenário de formação profissional que direcione para a compreensão de outras estratégias de ensino-aprendizagem.

Tendo em vista a importância dessa temática para a educação e para a formação de professores, a presente pesquisa teve como objetivo estudar o processo de desenvolvimento profissional de uma professora universitária quanto à utilização das novas tecnologias de informação e comunicação na sua prática docente. Compreende-se que essa pesquisa possa contribuir com professores e pesquisadores para uma maior clareza das variáveis envolvidas no desenvolvimento do professor, das diferentes etapas de sua formação e como tudo isso reflete na sua prática docente.

\section{Pilares teóricos}

Como opção teórica, três autores fundamentaram a análise dos dados obtidos pela história do desenvolvimento profissional, acadêmico e pessoal da professora universitária. Salienta-se que diante da vasta opção de pesquisas e teorias, escolher as que poderiam ser utilizadas como fundamento para o estudo dessa temática não foi tarefa fácil, mas reconhece-se que a 
escolha e a definição de bases teóricas para fundamentar as discussões dos resultados torna-se imprescindível para o desenvolvimento de uma pesquisa. Deste modo, procurou-se destacar três autores, que de um modo ou outro, estão intrinsecamente ligados para fins da análise dos dados.

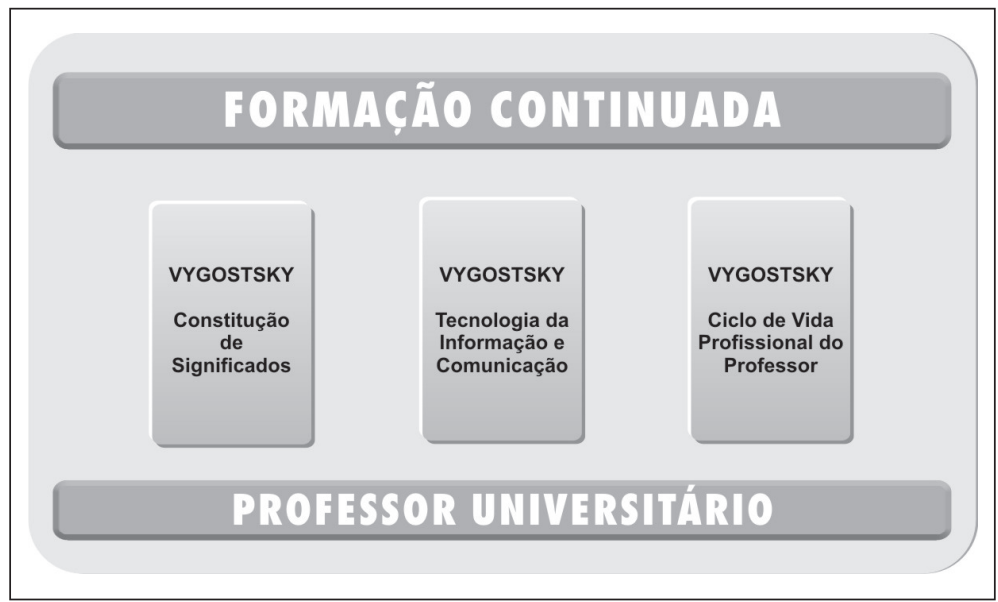

Figura 1 - Pilares teóricos para análise da formação continuada do professor universitário

Como primeiro pilar teórico, foi utilizado Michael Huberman, uma das referências bem citadas nas pesquisas sobre o desenvolvimento profissional do professor. Este autor analisa as fases comuns vividas pelos professores no ciclo profissional, apontando as possíveis influências entre a vida pessoal e profissional (JESUS; SANTOS, 2004).

Huberman (1992, p. 38) ressalta que "o desenvolvimento de uma carreira é, assim, um processo e não uma série de acontecimentos", mas que as pesquisas realizadas a partir da década de 70 apresentam características comuns a professores no mesmo período profissional. Ele acrescenta, ainda, que o entendimento do ciclo de vida do professor "trata-se, com efeito, de estudar o percurso de uma pessoa numa organização [...]" (HUBERMAN, 1992, p. 38). Uma melhor compreensão do processo, das mudanças, das vivências e das significações constituídas por estes profissionais ao longo de sua história ajudará a compreender "como as características dessa pessoa exercem influência sobre a organização e são, ao mesmo tempo, influenciadas por ela" (HUBERMAN, 1992, p. 38). 
Neste sentido, épreciso conheceros diferentes aspectos envolvidos na história pessoal e profissional daquele professor universitário que tem como escolha pessoal a busca permanente por novos conhecimentos, atualização, aperfeiçoamento metodológico, qualificação profissional, enfim, por formação contínua.

Huberman (1992) sintetizou, esquematicamente, os diversos estudos realizados em diferentes enfoques teóricos e metodológicos sobre o ciclo de vida profissional do professor, caracterizando fases predominantes ao longo da carreira. $\mathrm{O}$ modelo apresentado agrupa tendências de comportamento que vão da fase inicial de entrada na carreira, de um a três anos de experiência, caracterizada pelo tateamento, contato inicial e descoberta, até a fase final, com 35 a 40 anos de carreira, que tem como foco o desinvestimento. Essa fase "evoca um fenômeno de recuo e de interiorização no final da carreira profissional" (HUBERMAN, 1992, p. 46). É na caracterização comum dessa fase que se buscou a fundamentação para o primeiro pilar teórico e sustentação da escolha do sujeito de pesquisa que, mesmo podendo ser classificado nela pelo tempo de experiência profissional, difere em inúmeros pontos da caracterização comum e busca em novos aprendizados vislumbrar atividades profissionais futuras.

Outra variável envolvida neste estudo é a tecnologia de informação e comunicação, mais especificamente o seu uso pelo professor universitário e a influência dessa no desenvolvimento do docente. Para estabelecer o segundo pilar teórico, sem perder de vista o foco da pesquisa e a conexão teórica, buscou-se em Pierre Lévy - filósofo francês que se dedica ao estudo das interações entre a internet e a sociedade - a base para as discussões sobre as novas tecnologias de informação e de comunicação e sua estreita relação com o ambiente educacional. Muito mais do que estudar a rede mundial de computadores, Lévy (1997) aponta as inúmeras possibilidades de uso das ferramentas tecnológicas e as profundas mudanças vividas pela sociedade nas mais diferentes áreas.

O referido autor apresenta, também, a discussão da virtualidade, afirmando que "o virtual não se opõe ao real, mas sim ao atual" (LÉVY, 1997, p. 16). Muito além de conceitos está a compreensão das diferentes nuances da aplicação das ferramentas tecnológicas. Lévy (1997, p. 16) afirma que a "atualização aparece então como a solução de um problema". Entretanto, o uso das TICs no ensino superior não pode ser tratado de forma simplista e superficial. É como se simplesmente pelo ato de conhecer a ferramenta e pela capacitação tecnológica por meio de cursos breves, o professor 
estivesse apto ao efetivo e eficaz uso de novas ferramentas. "A atualização é criação, invenção de uma forma a partir de uma configuração dinâmica de forças e de finalidades" (LÉVY, 1997, p. 16). Muito além do conhecer a tecnologia disponível, é preciso que o professor saiba o que fazer com ela e como desenvolver atividades que possam contribuir efetivamente com o aprendizado do seu aluno.

Diante do dilúvio de informações que assola a sociedade, é preciso que cada professor estabeleça formas de filtragem, de seleção e de hierarquização (LÉVY, 1997). A disseminação da informação amplia as possibilidades de armazenagem, produção e socialização de grande quantidade de dados, estimula a comunicação, a autonomia e a criatividade (MATTOS, 1995,2001) e deve serentendida como a disponibilidade de recursos, de ferramentas, que podem contribuir no processo ensino-aprendizagem.

Mas a simples oferta não garante a produção de conhecimento. É preciso dar um sentido à informação. Outro aspecto relevante quanto à escolha de Pierre Lévy para o segundo pilar teórico está relacionado ao fato de que seus estudos não focam a informatização pura, de forma tecnicista. Esse autor aborda a tecnologia de informação e comunicação como "redes de interfaces abertas a novas conexões, imprevisíveis, que podem transformar radicalmente seu significado e uso" (LÉVY, 1997, p. 102).

Com ponto fundamental de interação teórica, Lévy estuda o homem enquanto um ser constituído na sua interação com o meio. Segundo suas palavras, "nós, seres humanos, jamais pensamos sozinhos ou sem ferramentas" (LÉVY, 1997, p. 95). A sua análise quanto ao pensamento e à linguagem reconhece as estruturas neurais de base, mas enfatiza que "O pensamento é profundamente histórico, datado e situado" (LÉVY, 1997, p. 95). Identificada a importância do contexto histórico, o autor enfoca, também, as relações sociais. Lévy (1997, p. 97) afirma que "não exercemos nossas faculdades mentais superiores senão em função de uma implicação em comunidades vivas com suas heranças, seus conflitos e seus projetos".

Nesse ponto de conexão, é apresentado o terceiro pilar teórico: Vygotsky. A teoria sociointeracionista de Vygotsky é ponto fundamental para a concretização do objetivo desta pesquisa. Esse pilar teórico traz a abordagem da constituição de significados por parte dos sujeitos. Para reconhecer as significações pessoais e profissionais do professor universitário é necessário entender a sua interação com o meio, com os instrumentos e consigo mesmo.

Rev. Diálogo Educ., Curitiba, v. 10, n. 30, p. 317-333, maio/ago. 2010 
O professor tem na tecnologia um instrumento de mediação na relação professor-aluno e no ensino-aprendizagem. Na sua interação com o meio, o ser humano passa a evoluir permanentemente, construindo novos conceitos, novas perspectivas e novas possibilidades. Para Vygotsky (2000, p. 24), "qualquer função psicológica superior foi externa - significa que ela foi social; antes de se tornar função, ela foi uma relação social entre duas pessoas". O desenvolvimento humano é mediado pelas relações sociais inseridas em determinado contexto histórico e é consolidado por meio da construção e reconstrução de significações individuais.

Vygostsky (1993, p. 129) destaca, ainda, que "um pensamento não tem equivalente imediato em palavras, a transição do pensamento para a palavra passa pelo significado”. Esse significado é construído por meio da relação do indivíduo com o meio, pela interação com o outro, pela mediação dos signos e pela construção e reconstrução conceitual. Para compreender a fala de alguém é preciso compreender o seu pensamento e a sua motivação (VYGOTSKY, 1993).

O imbricamento destes três pilares teóricos acompanhou a análise da história acadêmica e profissional de uma professora formadora. Concorda-se com Santos (2002) com relação ao processo de compreensão das análises sobre a formação continuada de professores. Para a autora, é preciso "compreender como sua história de vida e sua trajetória profissional se cruzam” (SANTOS, 2002, p. 91), referindo-se à formação docente. Santos acrescenta, ainda, que é preciso saber como a história pessoal e profissional vai "modelando seus comportamentos, suas perspectivas profissionais, sua visão e suas concepções”, referindose ao processo de formação docente. Concepções essas relacionadas à “educação, processo de ensino, organização do trabalho escolar, às políticas que orientam direta ou indiretamente sua prática pedagógica" (SANTOS, 2002, p. 91). Todo esse contexto torna-se relevante para as pesquisas que objetivam conhecer o processo de constituição identitária do professor.

Como indica Huberman (1992, p. 55), é preciso "ouvir a pessoa que fala. [...]. A pessoa que mais sabe de uma dada trajetória profissional é a pessoa que a viveu". Entende-se que "a maneira como essa pessoa define as situações com que se viu confrontada desempenha um papel primordial na explicação do que se passou" (HUBERMAN, 1992, p. 55). O reconhecimento da constituição dessas significações e do desenvolvimento 
pessoal e profissional do indivíduo só é possível a partir do contato com ele e por meio do relato de suas experiências.

Concorda-se com Goodson (2000, p. 69) quando este diz que "no mundo do desenvolvimento dos professores, o ingrediente principal que vem faltando é a voz do professor" 'grifo do autor]. Diante de tal situação, a pesquisa direcionou seus "ouvidos" para a voz da professora formadora para conhecer o processo de formação continuada e a relação com a sua identidade, significações e interações com os recursos tecnológicos.

\section{Procedimentos metodológicos}

A presente pesquisa foi realizada por meio do estudo de caso de tipo etnográfico que, como explicita André (2005, p. 31),

deve ser usado quando: 1) há interesse em conhecer uma instância em particular, 2) pretende-se compreender profundamente essa instância particular em sua complexidade e totalidade, 3) buscase retratar o dinamismo de uma situação numa forma muito próxima do seu acontecer natural.

A pesquisa foi realizada com uma professora universitária que trabalha em uma universidade comunitária, localizada ao sul do Brasil. Ana ${ }^{1}$ nasceu no ano de 1940, tem formação na área de Letras, 54 anos de experiência como professora e, desses, 33 anos de atuação como professora no ensino superior, no curso de Letras.

A coleta de dados foi realizada em oito encontros presenciais, nos quais foram realizadas entrevistas, observações e vivência com o uso de ferramentas tecnológicas. Também foram entrevistados alunos, exalunos e colegas de trabalho da professora. Os encontros ocorreram em diferentes momentos, sempre previamente agendados, com duração de aproximadamente uma hora cada um.

Foram seguidas as recomendações do Comitê de Ética no processo de pesquisa, bem como houve a assinatura da professora no Termo de Consentimento Livre Esclarecido (TCLE) e autorização para realização da pesquisa por parte da universidade comunitária na qual Ana trabalha.

\footnotetext{
${ }^{1}$ Nome fictício para preservar o anonimato do sujeito de pesquisa.
} 
A análise dos dados foi calcada no processo de interpretação relacional, no qual se prioriza a relação entre as informações obtidas pela coleta de dados. Esse procedimento possibilitou a apropriação e a generalização de conceitos e significados para uma melhor compreensão do processo de formação continuada na relação da professora com o uso da tecnologia de informação e comunicação no ambiente educacional.

\section{Resultados e discussão}

O ambiente familiar onde Ana cresceu era de cinco pessoas (pai, mãe, irmã, irmão e ela). Sua mãe dedicava-se aos cuidados com a casa, com o marido e com os filhos. O pai era funcionário público municipal e trabalhava como motorista. Foi alfabetizada em escola pública isolada que dispunha somente de séries iniciais, hoje encontradas nas primeiras séries do ensino fundamental. Segundo seu depoimento, sempre foi muito dedicada aos estudos, lia muito, tinha apoio dos pais, dos professores e de amigos da família.

Por causa das restritas condições socioeconômicas, a família não podia subsidiar a continuidade dos seus estudos, pois na cidade onde morava só existiam instituições particulares que ofereciam os estudos de $5^{\mathrm{a}}$ a $8^{\mathrm{a}}$ série. $\mathrm{O}$ apoio de pessoas ligadas ao meio profissional de seu pai viabilizou a continuidade da sua formação escolar em uma instituição privada.

A sua formação de professora iniciou com o Curso Normal e foi calcada em princípios cristãos que, segundo a professora Ana, era pautada pelo respeito aos valores humanos, postura ética e formação integral do ser humano. O referido curso iniciou no ano de 1956, logo após a conclusão do $2^{\circ}$ grau (atual ensino médio) e foi concluído no ano de 1957.

A partir do conhecimento desse contexto, constatou-se que a formação de Ana para o magistério enfatizou o aluno como centro do processo de ensino-aprendizagem, o respeito às características individuais e a valorização da construção do conhecimento. O seu desenvolvimento profissional foi calcado na visão do professor como um condutor do processo, como um mediador do aprendizado de seus alunos.

Pelos depoimentos, percebeu-se que a formação profissional da professora foi marcada pelo interesse em desenvolver atividades contextualizadas e direcionadas ao efetivo aprendizado de seus alunos. 
Infere-se que muitos dos seus saberes foram construídos por meio de sua experiência profissional. Para Romanowski (2007, p. 133), a construção de saberes "advêm da prática ao longo da carreira, que não atingem o estatuto pelo tempo e pela quantidade, e sim pela reflexão permanente, pelo confronto com os outros, com as teorias, e pela discussão coletiva". Mas nem por isso são experiências que rechaçam a importância de cursos e/ou de aprendizagens teóricas.

Quanto às tecnologias, Ana relata que sempre teve “aversão” a esses recursos. Ela explica que houve pouco interesse em aprender a mexer em equipamentos eletro-eletrônicos. Considerou que não houve necessidade, nem mesmo o desejo, de conhecer instrumentos tecnológicos. Compreendese mais claramente essa etapa do desenvolvimento a partir do entendimento da formação de conceitos. É um processo complexo e que "não pode ser reduzido à associação, à atenção, à formação de imagens, a inferências ou às tendências determinantes" (VYGOTSKY,1993, p. 50). Formar conceitos é construir significados, é compreender, é abstrair e generalizar. Durante a maior parte de sua trajetória pessoal e profissional, Ana não necessitou de ferramentas tecnológicas, o que não significa dizer que ela não as conhecia.

Segundo a professora, uma das suas principais características sempre foi conhecer o contexto dos conteúdos ensinados, compreender o todo para depois ir para as partes, para os detalhes. Esse preceito foi utilizado também no estudo dos recursos tecnológicos de informação e de comunicação. Antes de efetivamente utilizar o computador e a internet em sua prática profissional, participou de vários cursos introdutórios sobre o assunto, ingressou em cursos de capacitação para professores e buscou conhecer e reconhecer as novas tecnologias e sua utilização em sala de aula. Aos poucos, ela apropriou-se dos novos conceitos, por meio de recursos de abstração, generalização e aplicação na sua realidade.

Com tempo profissional para a aposentadoria, a professora não diminuiu seus esforços e entusiasmo pela busca de novas informações e construções de novos conhecimentos. Contrariando o comportamento característico de professores na fase do desinvestimento, a partir de 2003 Ana efetivamente começa a utilizar o computador para redigir textos, enviar e receber mensagens e pesquisar novas descobertas na sua área de atuação.

O reconhecimento inicial desses fatos foi extremamente instigante para o aprofundamento da coleta de dados na presente pesquisa. O contato com as ferramentas tecnológicas de informação e comunicação não foi feita 
"num piscar de olhos". Isso é esclarecido quando Nóvoa (2000,p. 16) explicita que a identidade é "um processo que necessita de tempo. Um tempo para refazer identidades, para acomodar inovações, para assimilar mudanças" [grifo do autor].

Os referenciais cognitivos foram sendo construídos ao longo de sua experiência, em inúmeros encontros com outras pessoas, em diferentes situações. Como afirma Romanowski (2007, p. 134), “a transposição para situações exemplares da prática, a inclusão nas reflexões, a relação com os problemas da prática também são desejáveis" para que ocorra o processo de desenvolvimento profissional.

Entretanto, o motivador que despertou a necessidade de utilização efetiva de tais ferramentas está relacionado ao seu planejamento de vida. Segundo a professora Ana, seu planejamento pessoal considera a atividade de revisão de textos após a aposentadoria e o afastamento institucional do trabalho. Somente quando percebeu que a utilização de instrumentos de envio e recebimento de informações seria imprescindível para que o seu objetivo fosse realizado, é que colocou em prática os conhecimentos sobre internet, microcomputadores, ambientes em rede e troca de mensagens. A partir disso, a sua mudança de atitude passa a ter um sentido pessoal, um significado, e reflete na sua atividade profissional.

Ela ressaltou que "sejá estivesse aposentada, em casa, eu acho que a internet não teria entrado na minha vida". Essa afirmação traz à tona a importância do convívio social e da interação com os outros como forma impulsionadora da formação continuada. Lévy (1997, p. 97) enfatiza que "antes de mais nada, jamais pensamos sozinhos, mas sempre na corrente de um diálogo ou de um multidiálogo, real ou imaginado". Por meio da influência do outro e do meio, a professora foi se inserindo no ambiente virtual e, a partir dessas interações, desenvolveu novas conceituações e novas significações que, associadas às já existentes e imbuídas de sentido próprio e individual, constituem valor e aplicabilidade.

Quanto à abordagem dos aspectos profissionais, a professora declarou que a partir do uso do computador e das ferramentas de comunicação e informação disponíveis na internet, as suas atividades foram facilitadas e o tempo de realização de seu trabalho diminuiu. Tanto as atividades na área administrativa quanto a preparação das aulas para os alunos do curso de Letras sofreram modificações. $\mathrm{Na}$ área administrativa, a internet é um meio de atualização com relação à legislação educacional; no processo 
de ensino-aprendizagem, a principal contribuição é a atualização quanto aos livros publicados e às pesquisas. Referindo-se ao uso da internet, ela enfatizou "boje eu vejo o quanto eu perdi em não ter começado antes".

Vygotsky (1993) lembra que os processos psicológicos superiores, nos quais há construção de conhecimento, nascem na vida social e, desta forma, são estabelecidos em duas etapas, uma interpsíquica outra intrapsíquica. Partindo dessa análise, a professora inicia o processo de aprendizagem com relação às tecnologias de informação e comunicação bem antes de ter internalizado os conceitos e ter dado um valor para o uso de ferramentas tecnológicas. Após vivenciar o uso da internet com o auxílio de amigos, ela percebeu que "bá muita coisa na internet que eu posso utilizar para confrontar com os textos trabalhados em sala", e essa tem se caracterizado como sua prática.

Cabe ressaltar que o uso da tecnologia tem contribuído não só como ferramenta, mas também como meio de aproximação da professora com seus alunos. Para a professora, a relação com os alunos ficou mais próxima, pois pode acompanhar a conversa quando falam de sites de busca, como o Google, sites de relacionamento, como o Orkut, ou recursos de comunicação online, como o MSN. Conhecer esses termos permitiu a manutenção do diálogo, o estímulo à construção de novos conhecimentos, à compreensão do contexto e à consolidação de uma efetiva via de comunicação.

Ao investigar as principais mudanças na sua atuação profissional, constatou-se que as novas tecnologias integraram-se a sua prática docente como mais uma dentre tantas ferramentas já utilizadas pela professora. Segundo ela, "de certa forma, a internet sempre esteve presente nas aulas, mas os acadêmicos realizavam aspesquisas. Agora eu também pesquiso e seleciono os textos".

Quando verificados quais os estímulos externos envolvidos no processo de mudança do posicionamento da professora quanto ao uso das ferramentas tecnológicas, a busca por capacitação, ela relatou que vivenciou uma solicitação de trabalho de revisão de texto por pessoas de outras cidades que necessitavam comunicar-se com ela utilizando o e-mail para troca de mensagens. Nesse sentido, Vygotsky (2000, p. 53) salienta que as funções cognitivas elementares "têm como característica fundamental o fato de serem total e diretamente determinadas pela estimulação ambiental". A partir deste fato, a professora começou a ter um interesse efetivo pelas ferramentas tecnológicas para auxiliar em seus trabalhos. 
Quantos aos estímulos internos, a professora Ana faz referência ao desejo de dedicar-se à atividade de revisão de texto após o seu afastamento institucional do trabalho. É uma atividade na qual se realiza, sente satisfação e será uma realização pessoal poder dedicar seu tempo a esta prática. Conforme afirmou: "tenho a intenção de não parar de uma vez. Como aposentada, desejo fazer trabalhos de revisão em casa". Nesse sentido, a professora compreendeu que os recursos tecnológicos são utilizados pela maioria das pessoas e que "as pessoas acham que é mais fácil enviar os textos por e-mail'. Seu interesse pelo uso de alguns recursos tecnológicos foi explicitado quando afirmou que "ou eu aprendo a utilizar os recursos ou não vou conseguir fazer aquilo que é meu desejo".

Nóvoa (2000, p. 17) contribui com esta questão do projeto pessoal quando explicita que "as opções que cada um de nós tem de fazer como professor, as quais cruzam a nossa maneira de ser com a nossa maneira de ensinar e desvendam na nossa maneira de ensinar nossa maneira de ser. É impossível separar o eu profissional do eu pessoal" [grifos do autor]. Deste modo, pode-se afirmar que todo o seu processo de formação continuada foi desenvolvido pelos desafios advindos das atividades educacionais, bem como de outras necessidades demandadas por sua história de vida.

\section{Considerações finais}

A última década foi marcada pelo intenso avanço no uso de tecnologias de comunicação e informação em todos os setores da sociedade. Como não poderia deixar de ser, também o processo de ensino-aprendizagem recebeu a influência de novas técnicas, ferramentas e metodologias.

Nesse movimento de construção de características peculiares no contexto social e de trabalho, os processos formativos e de constituição identitária dos professores tendem a acompanhar as demandas advindas do universo laboral. Como esclarece Nóvoa (2000, p. 16), "a identidade não é um dado adquirido, não é uma propriedade, não é um produto. A identidade é um lugar de lutas e de conflitos, é um espaço de construção de maneira de ser e estar na profissão".

Mas, quais as significações constituídas pela professora Ana ao longo do seu desenvolvimento pessoal e profissional diante do uso das TICs na sua prática docente? Como essas ferramentas foram sendo 
incorporadas em suas aprendizagens? Que processos de formação continuada foram ocorrendo para que a professora fosse internalizando experiências relacionadas aos processos tecnológicos? Diante dos dados, infere-se que a atuação da professora está calcada na abstração e na generalização de conceitos apreendidos nas interações sociais, culturais e no contexto histórico de cada época.

Ela utiliza a internet como um dos possíveis recursos para preparar suas aulas, mas, antes de trabalhar o conteúdo com os alunos, faz uma triagem, verifica o que realmente pode ser utilizado, o que está desatualizado e o que precisa de reflexão crítica. A sua postura é de utilizar a internet como uma ferramenta que oportuniza o exercício da escrita e de investigação complementar.

O estudo de caso permitiu conhecer os aspectos pessoais, profissionais e sociais relacionados às suas inter-relações. A utilização dos recursos tecnológicos é uma opção complementar, uma ferramenta didático-pedagógica que auxilia de forma positiva e enriquecedora. Mas não é decisiva nem determinante no que se refere a sua competência como professora universitária.

As características de responsabilidade, comprometimento, atualização, pesquisa, dedicação, respeito, interação com os alunos, dentre tantos outros aspectos relevantes, sempre calcaram a sua atuação como professora. É justamente essa postura que faz com que ela busque novos recursos de comunicação e informação.

Não é o ato de utilizar as ferramentas tecnológicas disponíveis que irá garantir que o professor está preparado para conduzir o processo de ensino-aprendizagem em tempos de internet, de ambientes virtuais de aprendizagem e de mundialização da informação. A profissionalização deve permear a sua postura como docente, enfatizando o desenvolvimento de habilidades e competências que possibilitem atitudes adequadas à nova realidade do ambiente universitário.

A utilização do computador, internet ou multimídia é uma demanda concreta do ambiente universitário. Entretanto, nada disso faz sentido se a formação do professor não estiver fundamentada em concepções de ensino-aprendizagem focadas no estudante, no ser humano, em ações reflexivas e inovadoras. As novas ferramentas também devem privilegiar a construção de conhecimentos de forma interativa, integrada e participativa que poderão, sim, ser mediadas pelo uso das novas tecnologias, 
mas que sempre terão como objetivo final o crescimento cognitivo e o desenvolvimento do ser humano com um ser social.

Para que tal situação ocorra, considera-se a formação continuada essencial aos professores universitários, de modo que as práticas pedagógicas, bem como a utilização de novos recursos tecnológicos, possam fundamentar o trabalho desenvolvido em sala de aula. Concorda-se com Romanowski (2007, p. 138), quando afirma que "a formação continuada é uma exigência para os tempos atuais". A autora ressalta que "pode-se afirmar que a formação docente acontece em continuum" e acrescenta que essa formação é "iniciada com a escolarização básica, que depois se complementa nos cursos de formação inicial, com instrumentalização do professor para agir na prática social, para atuar no mundo e mercado de trabalho". Mas não acontece somente em momentos específicos da constituição da docência. "Continua ao longo da carreira do professor pela reflexão constante sobre a prática, continuidade de estudos, programas e projetos" (ROMANOWSKI, 2007, p. 138).

O desenvolvimento profissional da professora formadora pode mostrar como sua história com as tecnologias foi permeada pelo interesse em proporcionar outros significados à aprendizagem dos estudantes e, principalmente, ao seu processo de formação contínua. Como evidencia Goodson (2000, p. 72), "as experiências de vida e o ambiente sociocultural são obviamente ingredientes-chave da pessoa que somos, do nosso sentido do eu". O autor citado enfatiza ainda que, "de acordo com o 'quanto' investimos o nosso 'eu' no nosso ensino, na nossa experiência e no nosso ambiente sociocultural, assim concebemos a nossa prática” [grifos do autor].

\section{Referências}

ANDRÉ, M. E. D. A. de. Estudo de caso em pesquisa e avaliação educacional. Brasília: Líber Livro, 2005.

GOODSON, I. F. Dar voz ao professor: as histórias de vida dos professores e o seu desenvolvimento profissional. In: NÓVOA, A. (Org.). Vida de professores. Portugal: Porto, 2000. p. 79-110.

HUBERMAN, M. O ciclo de vida profissional dos professores. In: NOVOA, A. Vidas de professores. Porto: Porto, 1992. p. 31-61. 
JESUS, S. N. de; SANTOS, J. C. V. Desenvolvimento profissional e motivação dos professores. Revista Educação, ano 27, n. 1, p. 39-58, 2004. Disponível em: <http://caioba.pucrs.br/faced/ojs/index.php/faced/article/viewFile/373/270>. Acesso em: 19 nov. 2008.

LÉVY, P. O que é virtual? São Paulo: Editora 34, 1997.

MATTOS, S. A revolução dos instrumentos de comunicação com os públicos: como atingir com eficácia os públicos da empresa em tempo de internet e superrodovia da informação. Porto Alegre: Comunicação Integrada Editores, 1995.

- Os modernos instrumentos de comunicação organizacional. Rastros Revista virtual do Núcleo de Estudos em Comunicação, ano 3, n. 3, 2001. Disponível em: <http://www.revistas.univerciencia.org/index.php/rastros/ article/view/6058/5524>. Acesso em: 20 nov. 2008.

NÓVOA, A. Vida de professores. Portugal: Porto Editora, 2000.

ROMANOWSKI, J. P. Formação e profissionalização docente. Curitiba: Ibpex, 2007.

SANTOS, L. L. de C. P. Formação de professores e saberes docentes. In: SHIGUNOV NETO, A. S.; MACIEL, L. S. B. (Org.). Reflexões sobre a formação de professores. Campinas, SP: Papirus, 2002. p. 89-102.

VYGOTSKY, L. S. Pensamento e linguagem. São Paulo: Martins Fontes, 1993.

.Vygotsky: manuscrito de 1929. Revista Educação e Sociedade, v. 21, n. 71, p. $24-40,2000$.

Recebido: 04/05/2009

Received: 05/04/2009

Aprovado: 09/06/2009

Approved: 06/09/2009 